\title{
EMOTIONALLY MEDIATED SYNAESTHESIA
}

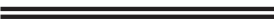 \\ Jamie Ward \\ University College London, UK
}

This study reports a synaesthete, GW, who experiences synaesthetic colours in response to a limited range of stimuli-namely those that have an emotional connotation. GW is significantly more consistent than a group of controls, and shows a Stroop-like congruency effect when the text colour differs from that reported for her synaesthetic photisms. The names of people who are known personally to GW are more likely to induce a synaesthetic colour than names referring to people with whom she is not personally acquainted and other categories of word (including colour names themselves). This feature resembles a number of reports in the historical literature on synaesthesia. This is explained by the fact that these stimuli are more likely to elicit an emotional response. In support of this, other words that have an emotional connotation (e.g., "love") have a tendency to elicit a synaesthetic response. The valence of the emotion (positive vs. negative) may have some role to play in determining the colour of the stimulus. It is concluded that emotion-colour synaesthesia is a genuine, if unusual, form of synaesthesia.

\section{INTRODUCTION}

Synaesthesia is the involuntary perceptual experience in one sensory modality that is normally associated with another perceptual modality or with amodal cognitive processing. For instance, synaesthetes may experience colours (e.g., BaronCohen, Harrison, Goldstein, \& Wyke, 1993) or taste (e.g., Ward \& Simner, 2003) in response to hearing or producing speech. The actual synaesthetic experience has been termed the concurrent and the stimulus that triggers it termed the inducer (Grossenbacher \& Lovelace, 2001). The synaesthete's subjective reports (e.g., "dark blue colour"), can be backed up by a number of objective tests including synaesthetic Stroop (e.g., Mattingley, Rich, \& Bradshaw, 2001; Mills, Boteler, \& Oliver, 1999; Odgaard, Flowers, \& Bradman, 1999) and perceptual grouping
(Ramachandran \& Hubbard, 2001a). However, the level of representation of the inducing stimulus that triggers the synaesthesia can often be ambiguous and it needs to be empirically determined. For example, consider the spoken word "love." This can be described in terms of acoustic features that differ, say, from a male to a female speaker. It can also be described phonemically such that it is invariant across these acoustic changes. It can be described lexically (i.e., this is a known word in the vocabulary), conceptually, and contextually (e.g., a term of endearment or a score in tennis). The word also may elicit an emotional reaction. Furthermore, the spoken form can be transformed into its orthographic representation (L-O-V-E), which itself can be represented at multiple levels (e.g., with or without case specification).

The precise level of representation that drives the synaesthesia varies from person to person. Some

Correspondence should be addressed to Jamie Ward, Department of Psychology, University College London, Gower Street, London, WC1E 6BT, UK (Email: jamie.ward@ucl.ac.uk). 
synaesthetes with "coloured-hearing" have colours induced by both speech and nonspeech, implying that the inducer is at a relatively low level of sound analysis (e.g., Masson, 1952; Myers, 1911). Others may have it for speech but not for similar acoustic material (e.g., Nunn et al., 2002) and some may even show a dissociation between words and nonwords, suggesting a much more abstract level of synaesthetic induction (e.g., Baron-Cohen, Wyke, \& Binnie, 1987). The case that is presented here is unusual in that we postulate that it is the affective component of a word (or other stimulus) that directly triggers a synaesthetic sensation of colour. This can be empirically demonstrated in a number of ways. First, stimuli with an emotional connotation may be more likely to induce a synaesthetic response than those that do not. One class of stimuli that this would particularly apply to would be the category of personally familiar people, because emotion is an integral part of our social world. Second, the particular hue of the synaesthetic photism may relate to the emotional valence (e.g., negative emotions being associated with particular hues). There are five case descriptions in the literature published in the early 20th century that, to a greater or lesser extent, fit this pattern (Collins, 1929; Cutsforth, 1925; Raines, 1909; Riggs \& Karwoski, 1934; Whipple, 1900), together with a number of brief reports in the contemporary literature (Cytowic, 1989; Weiss, Shah, Toni, Zilles, \& Fink, 2001). These are summarised below.

\section{Synaesthesia induced by emotions}

The case most similar to the one that I shall report below was documented by Riggs and Karwoski (1934). Their 7-year-old synaesthete associated colours with people. The colours were often projected on to the people (e.g., their lips). Their observations suggest that the colour is fixed by degree of acquaintance rather than physical characteristics. For instance, plaster cast heads elicited no subjective colour but all real strangers are described as being "bright orange with a black outline" and "As I know them better they get mild blue or pinkish orchid ... When I know people well they stop changing colours; they are the colour" (p. 32). When taken to watch Oliver Twist at the cinema, Fagan and the Artful Dodger were black, Oliver was light blue, Nancy was red or green, and so on. One month later, when asked to categorise coloured yarns according to pleasantness, his groupings were appropriate to the previous characterisations (black, grey, and brown being unpleasant, and rich saturated colours being identified with people he was positively disposed towards). Riggs and Karwoski argued that the synaesthete's own internal, affective reaction to a stimulus can act as a determinant of synaesthetic colour.

Collins's (1929) synaesthete, S, also associated colours with people. She noted that: "Individuals of no interest to $S$, or not well known to $S$, or of unimpressive personality, have no colour. The colours of individuals are liable to change as $\mathrm{S}$ becomes acquainted with them" (p. 13). In this case, the synaesthesia is by no means restricted to people or even to colours. Pure tones, vowels, and numbers all have colour, and smell is also often elicited as a synaesthetic experience. Nevertheless, there are a number of interesting observations that suggest that the synaesthesia is determined, at least in part, by factors other than the perceptual properties of stimuli. The colour of people can change even though their names, faces, and voices presumably do not. Furthermore, Collins reports that all things disagreeable elicit the same colour (e.g., a discordant note played on the piano or in a song).

Cutsforth's (1925) detailed case study describes how various stimuli (e.g., smells, days, sounds) are coloured by affective influences. For instance, tones would tend to be coloured according to pitch unless the tone's pitch and/or intensity were increased to the point at which it became unpleasent, in which case it would take on the hue appropriate for this affective state. The affective colours are often superimposed on the visual scene. For example, the subject relates the following incident: "Read of the death of a near neighbour; the newspaper suddenly turned green and took on a swirling motion; as I read the details the colour faded somewhat but for several hours my imagery took on a greenish cast. Later in the day I picked up the American 
Magazine and discovered a reference to an old acquaintance. The green cast changed to colours characteristic of happier moods-rose, orchid and cream-yellow" (p. 539).

The two cases reported by Raines (1909) and Whipple (1900) are harder to interpret because the descriptions are less detailed and there appear to be other forms of synaesthesia co-occurring. Raines reports that "only certain persons produce the sensation of colour" (p. 250), and that certain emotions (e.g., happiness, desire) have colour both "as a word or as an emotion" (p. 251). Whipple explicitly interpreted case M's synaesthesia as occurring via an affective process. Neither words nor letters were coloured, but affectively toned Christian names could elicit a colour and letters often elicited emotional responses and personifications (e.g., $\mathrm{D}$ = stupid, $\mathrm{C}$ = good-natured, $\mathrm{N}=$ agreeable).

In the more recent literature on synaesthesia, Cytowic (1989) notes two synaesthetes who associate coloured "auras" with people, which appears to be affectively linked. For BB: "The stimulus seems to come from the people themselves, who have colors around them. It feels like an emotional bond. The feeling lasts a few seconds ... sometimes I think I see the color and react emotionally; others it may be reversed-I get an emotion and then see this colour" (pp. 50-51). Similarly for DS, a suspicion that somebody is no good produces a "colour spike" that "she feels is entirely based on her feelings [about that person].” (p. 50). Although both of these reports are anecdotal, they fit with the earlier literature in the sense that it is the emotional responsiveness of the perceiver that seems critical in these synaesthetes.

Finally, Weiss et al. (2001) reported a single case study of a synaesthete who reported reliable synaesthetic experiences given the names of personally familiar people, but not unfamiliar people. This was interpreted as a case of "chromatic-lexical" synaesthesia because the colour of words was not derived from the (presumably colourless) letters and phonemes that make up the word. However, no explanation was given as to why the synaesthesia should be restricted to the category of personally familiar names, and nor was it clear whether colours were noted for any other type of stimulus (e.g., emotionally-loaded words).

\section{Other influences of emotion on synaesthesia}

Other studies of synaesthesia have suggested a more indirect role of emotions in the synaesthetic experience. Many synaesthetic experiences are accompanied by a strong emotional reaction (Cytowic, 1989). The fact that synaesthetic experiences can be emotional was one of the factors that lead Cytowic to postulate a limbic basis for them. A more recent theory has postulated hyperconnectivity between limbic regions (responsible for emotion) and cortical regions, such as the fusiform, that are involved in visual recognition and colour processing (Ramachandran \& Hubbard, 2001b). Nunn et al. (2002) did indeed report activity in the left retrosplenial cortex in their synaesthetic subjects (word/grapheme $\rightarrow$ colour synaesthetes) relative to controls (see also Weiss et al., 2001). They interpreted this activity as reflecting a possible emotional component of synaesthetic experiences (e.g., Maddock, 1999).

There is some evidence to suggest that colouremotion associations also exist in nonsynaesthetes. Collier (1996) reported that subjects tend to choose the colour blue for "sad," yellow for "cheerful," gold for "proud," and so on. Similarly, positive emotions tend to be mapped onto rounded forms and negative ones onto angular forms. The extent to which these reflect arbitrary cultural associations is not clear. D'Andrade and Egan (1974) found consistent colour-emotion associations between Western culture and a culture with minimal Western contact. Even if it could be demonstrated that such correspondences were universal there would still remain one key difference between this and synaethesia, in terms of the phenomenology. Synaesthetes report their colour experiences to be automatic and perceptual (or percept-like) in character. In the study reported below, control subjects were also required to generate colours for certain stimuli as a way of distinguishing between our synaesthete and nonsynaethetes who may have cultural colour associations. 


\section{CASE REPORT}

GW is a 19-year-old, right-handed student. She experiences colours in response to certain people and to a lesser extent to some words, letters, and numerals. Colours elicited by words are perceived as occupying the whole field of vision, but are not projected onto the external stimuli. Faces and some objects can also often appear to have visual halos or "auras" which are coloured, and projected around them. A synaesthetic taste is occasionally elicited, which has subjective location on the tongue. The taste responses were too infrequent (less than 1\% of responses) to analyse or test objectively and this study therefore concentrates on colour. GW claims to have had the sensations all her life but only became aware that she was different from other people at about 7 years of age. She has not asked her family about any similar sensations they may experience. On the NART (Nelson, 1985) she scored 31/50, which gives her an estimated IQ of 112. In order to determine whether she has superior verbal associative learning she was given the paired associates test of Warrington (1996). This consists of learning three sets of eight word pairs (e.g., barnfarmer), which are recalled in two consecutive trials. On the first trial she scored 16/24 (performing at the 18th percentile for age-matched controls) and on the second trial she scored 23/24 (27th percentile). It seems unlikely that superior verbal associative memory could account for her synaesthetic associations.

\section{EXPERIMENTAL INVESTIGATION}

The studies carried out with GW were motivated by a comment that she made during one testing session. It was noted that people's names (e.g., "James") appeared to elicit a synaesthetic response more than other stimuli such as names of colours (e.g., "red") or food (e.g., "strawberry"). She commented that when she gets to know new people then they often acquire a synaesthetic colour. When presented with that person's name or face, the colour appears inevitably and spontaneously and cannot be suppressed. This was considered to be of interest because of the very similar descriptions reported in the historical literature. Before examining the nature of the synaesthesia in more detail it is important to establish, objectively, that the experiences she reports are genuine. One "test of genuineness" consists of showing that the perceptual experiences are more consistent over time than would be expected from memory alone (e.g., Baron-Cohen et al., 1993; Harrison, 2001). Another test that has been extensively used to show that the experiences are both genuine and automatic is the synaesthetic variant of the Stroop test, in which colour naming is found to be slowed when the true colour of a stimulus conflicts with that generated by the synaesthesia (e.g., Mattingley et al., 2001; Mills et al., 1999; Odgaard et al., 1999).

\section{Consistency}

GW was given 83 words and asked to report any synaesthetic photisms. This was repeated 1 week later, and again 4 months later. The control subjects $(N=7)$ were given the same list twice, separated by 1 week, but were asked to generate colours for every stimulus in such a way that might aid later memory. The words were presented in a different order on the second occasion. Preliminary testing of GW had shown that many words elicit no colour at all. Thus, in order to avoid the possibility that she could obtain high levels of consistency by claiming "no colour" for a high proportion of stimuli, the items selected were chosen from particular categories. Sixty-two words were common English Christian names (a category that will be shown to be a potent inducer of colours), and the remainder were words which that been shown to elicit a colour response on a previous occasion. In addition, both GW and controls were asked to note down the names of 15 personal acquaintances and generate colour associations for each person on two occasions separated by a week. GW was also assessed again after a further 4 months. The degree of personal acquaintance will be shown to be a key influence in GW's synaesthesia and so it was considered important to assess this in control participants too.

For the 83 words, GW was $82 \%$ consistent after 1 week, which is significantly higher than controls 
(mean $=49.4 \%, S D=7.3 ; Z=4.46, p<.001)$. If one considers only those words that generated a colour on both occasions (some $63 \%$ of stimuli), then the consistency level is $87 \%$ compared to $46.5 \%$ for the same items in the control group $(S D=7.3 ; Z=$ $5.55, p<.001) .{ }^{1}$ This suggests that it is not intrinsically easier to generate consistent associations to this subset of words. The high level of consistency was maintained after 4 months ( $76 \%$ consistent). Similarly, GW is $87 \%$ consistent for the 15 names of personal acquaintances (after both 1 week and 4 months) compared to $51.4 \%$ from controls, who were also asked to generate 15 name-colour pairs of their choice (after a 1-week retention interval). GW's level of consistency is outside of the range of scores from control subjects ( $27 \%$ to $80 \%)$, but is only of borderline statistical significance because of the large individual variation $(S D=19.9 ; Z=1.81$, $p=.07$, two-tailed). The next section will show that for GW, but not for controls, the links between colour and these personal acquaintances are elicited automatically (e.g., Mattingley et al., 2001; Mills et al., 1999; Odgaard et al., 1999).

In summary, this section has demonstrated that there is a tendency for GW to be more consistent than controls, despite the fact that her memory for paired associations in general is not superior. We attribute this discrepancy to synaesthesia.

\section{Synaesthetic Stroop effect}

Fourteen people's names were selected: GW had previously reported colour associations to them all. Each name was presented 10 times: 5 times in the congruent condition, in which the text colour was the same as the synaesthetic colour, and 5 times in the incongruent condition. The incongruent condition used the same set of colours as the congruent condition but the colours were paired up with a different inducing name. The 140 stimuli were presented in a random order on a grey background computer screen. Prior to each stimulus being displayed there was a fixation cross presented for
$1000 \mathrm{~ms}$. This was followed by the stimulus, which remained on the screen until the subject named the colour into a microphone as quickly and accurately as possible. The same set of stimuli were presented twice, in two consecutive blocks, under two different sets of instructions. The first condition required $\mathrm{GW}$ to name the text colour to determine whether synaesthesia interferes with colour naming. The second condition required her to name the colour of the synaesthetic photism elicited. This would determine whether the presence of the text colour interferes with synaesthetic photism naming (see Smilek \& Dixon, 2002).

The control subjects $(N=7)$ were given the same 140 -item list as GW in the text colour naming instructions. In addition they were given an individual Stroop experiment based on the colours associated with personal acquaintances of their own (see "consistency" section), which also used the text colour naming instructions. This condition ensures that any effects observed with GW are not just due the fact that the experiment was set up using the names of people who are close to her.

The results from GW were analysed in a $2 \times 2$ ANOVA, with the first factor being instruction (name text colour, name synaesthetic colour) and the second being congruency (congruent, incongruent). Incorrect responses and technical errors (e.g., microphone not responding) were excluded from the analysis (8.8\% of trials). The results are summarised in Figure 1. There was a significant main effect of congruency $F(1,256)=131.31, p<$ .001. The fact that GW shows a synaesthetic Stroop effect suggests that these photisms are genuine and automatically elicited. The effect of congruency was stronger in the photism naming than the text colour naming condition: interaction $F(1,256)=10.72, p<.001$. The photism naming condition was slower because of interference on the incongruent trials: main effect of instruction $F(1,256)=9.59 . p<.005 . \mathrm{GW}$ is just as fast at naming synaesthetic photisms as text colour when there is no conflict between them, $t(126)=0.16$, ns.

\footnotetext{
${ }^{1}$ The inconsistent items, such as there were, resulted both from changes between colour present and colour absent, and also some changes in the hue response.
} 


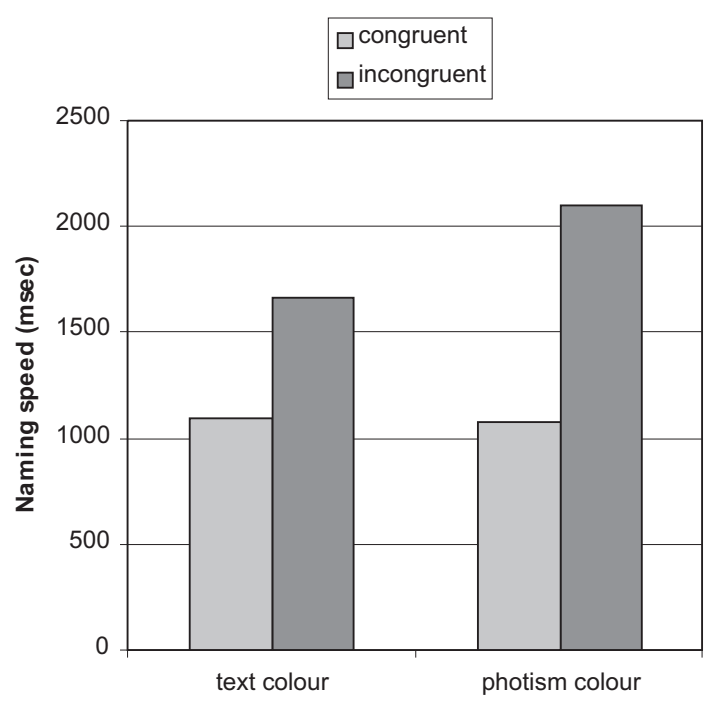

Figure 1. Colour naming latencies for congruent and incongruent stimuli, when asked to name the text colour or the synaesthetic colour.

Mills et al. (1999) also showed that there was no difference in naming time for congruent text colour and synaesthetic colour when printed in a neutral black text, but they did not have photism colour naming in an incongruent condition. Smilek and Dixon (2002) report that some synaesthetes show greater congruent-incongruent differences when asked to name synaesthetic colours relative to text colours (as in GW), whereas other synaesthetes show the reverse pattern. This could be explained by the relative strengths of the "real" versus synaesthetic colour (the former being harder to suppress in GW).

For the control subjects, there was no significant difference between congruent and incongruent trials using GW's colour associations, $t(6)=1.01$, $\mathrm{ns}$; mean congruent $=592 \mathrm{~ms}$, mean incongruent = $603 \mathrm{~ms} ; 5 \%$ of responses excluded because of error or microphone problems. Nor was there any congruency effect using the lists of personal acquaintances and colours generated by the control subjects themselves, $t(6)=0.72$, ns; mean congruent $=582 \mathrm{~ms}$, mean incongruent $=579 \mathrm{~ms} ; 2 \%$ of responses excluded because of error or microphone problems. Thus, control subjects show no evidence of a congruency effect even when names of their own personal acquaintances are used in conjunction with colour responses generated by themselves.

\section{Synaesthesia for names?}

In order to establish whether people's names do indeed have a "special" status as synaesthetic inducers it is important to compare the rate of synaesthetic responses to these words to words from other categories, matching for potentially confounding variables. The first list contained 150 words from five different semantic categories: countries, first/Christian names, objects, animals, and food. The second list contained 161 items taken from 10 different categories: animals, first names, colour names, countries, family (e.g., father), food, furniture, body parts, plants, and transport. In both lists, the words in each category were matched for word length, and tabulated word frequency (Carroll, Davies, \& Richman, 1971). Figure 2 shows the number of synaesthetic responses generated by different semantic categories in two different lists. The first thing to note is the general paucity of synaesthetic responses. Fewer than a quarter of all words produce any synaesthetic response at all. This differs from other sorts of synaesthesia in which, say, the colour is determined by the first letter. In these instances, the synaesthesia is highly productive, with virtually all stimuli producing a synaesthetic response (Ward, Simner, \&Auyeung, in press). The second thing to note is that the category of names produces the most responses in both lists. Comparing Christian names with all other categories produced a significant result for the first list (Fisher's Exact test, $p<$ .05 , two-tailed) and a borderline significant result for the second list (Fisher's Exact test, $p<.05$, onetailed). These are unlikely to reflect purely verbal associations. For instance, none of the colour names (e.g., "yellow," "pink") elicited a synaesthetic percept and very few of the food names (e.g., "strawberry," "carrot") did either. This is in spite of the fact that these items have a well-known conventional colour. In contrast, the name "James" is pink, "Thomas" is black, "Hannah" is blue, and so on. 

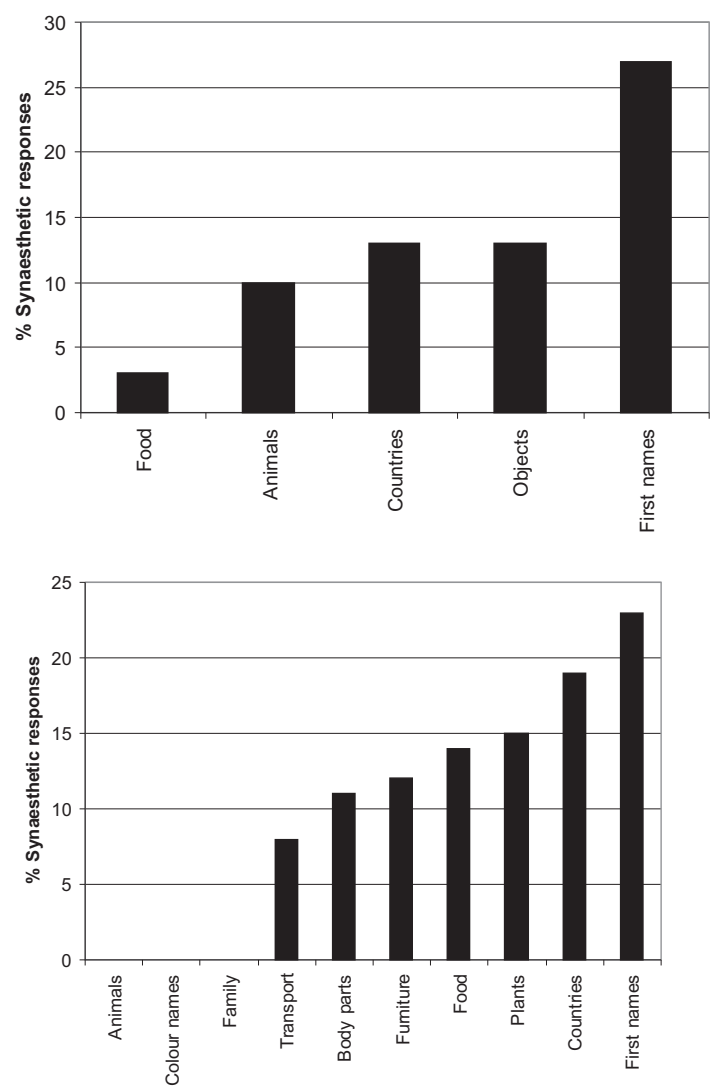

Figure 2. Percentage of synaesthetic responses for various semantic categories of word. The upper graph contains higher-frequency words than the lower graph.

It will be shown that this effect is greatly accentuated if one takes in to account whether GW actually knows anyone personally with these names, as noted in previous cases (e.g., Collins, 1929; Weiss et al., 2001).

\section{Influence of personal acquaintance}

GW was given 131 names and asked to rate each one according to how well she personally knows someone with that name on a 3-point scale: well known, vaguely known, and not known. This was done in a separate session from the previous experiments that looked at synaesthesia for these names. It should be noted that the names classed as "unknown" were familiar names to GW (i.e., they were not equivalent to nonwords) but she just wasn't personally acquainted with anyone of those names. Having established this, we then went back and found out whether these names had an associated synaesthetic colour or not. Figure 3 shows that personal familiarity strongly predicts whether a synaesthetic colour will be elicited for that name, $\chi^{2}(2)=65.51, p<.001$.

Finding an association between synaesthesia and personal experience is not a trivial finding because some theories of synaesthesia have speculated that the synaesthetic mechanisms are established at birth or very soon after (Baron-Cohen, 1996). These findings suggest that the synaesthetic correspondences can be shaped by experience much later in life. However, it will be argued that personal acquaintance exerts its influence on synaesthesia by tapping more basic associations between emotion and colour that could well have been in place from an early age. The next section evaluates the hypothesis that the synaesthesia for familiar people could relate to their emotional arousability.

\section{Synaesthesia for emotional words}

One hundred and eight nouns were selected from the norms of Brown and Ure (1969). These words had been rated for emotionality (1-7 scale, where 1 is unemotional and 7 is highly emotional) and goodness (1-7 scale, where 1 is very pleasant, 4 is

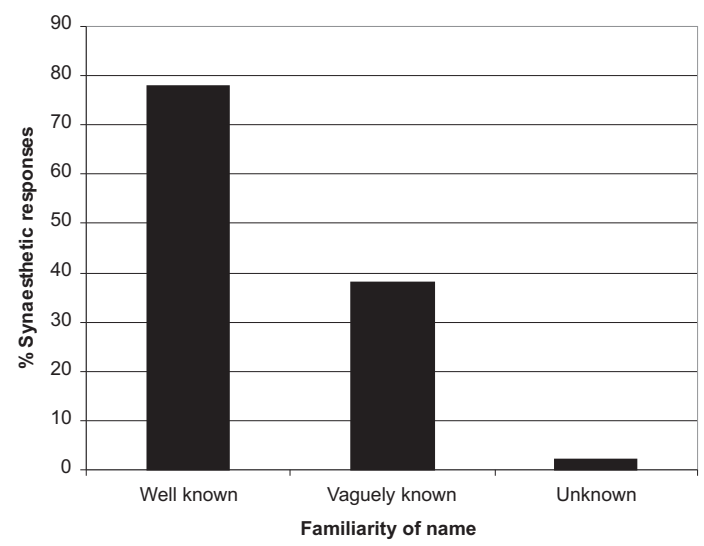

Figure 3. Influence of name familiarity on the probability of a synaesthetic response. 
neutral, and 7 is very unpleasant). The words were presented in a random order centrally on a computer screen, twice over two sessions. The test was self-paced and GW noted any synaesthetic sensations to the experimenter. A subset of these responses had been used as part of the measure of consistency, described above. Figure 4 shows the number of synaesthetic responses for highly emotional words (ratings greater than 6), moderately high emotional words (ratings between 5 and 6 ), and low emotionality words (ratings less than 3.5). There was a significant difference across categories, $\chi^{2}(2)=8.59, p<.05$.

A synaesthetic response was just as likely for a highly emotional word irrespective of whether the emotion was positive or negative in valence. A logistic regression on the data (presence or absence of a synaesthetic response) suggested that emotionality was a significant predictor (Wald $=6.63, p<$ $.01)$, but the potentially confounding variables of imageability (Wald $=0.10$, ns), and word frequency $(\mathrm{Wald}=0.00, n s)$ were not. The length of the word (Wald $=3.77, p=.06)$ and the goodness (Wald $=3.63, p=.06$ ) were borderline significant. This suggests that the effect of emotionality is genuine and is consistent with the hypothesis that it is this factor that underlies the synaesthetic response to personally known people. Although goodness is not a strong predictor of synaesthesia it does appear to influence the colour that is generated. This is examined in the next section.

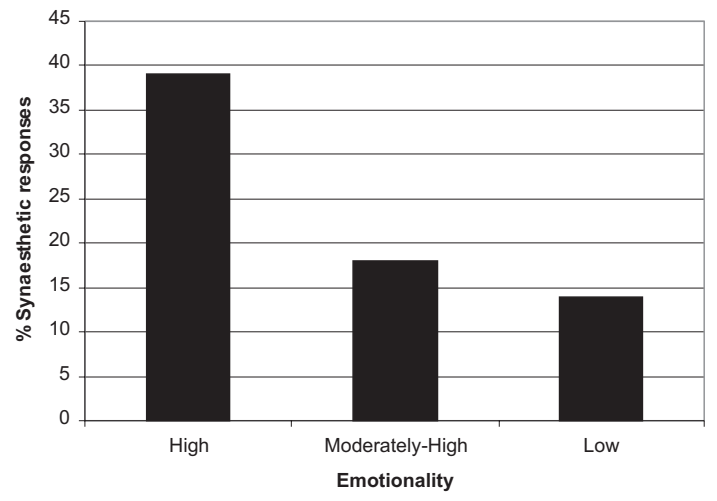

Figure 4. Effect of emotionality on the probability of a synaesthetic response for common nouns.

\section{Influence of emotional valence on synaesthetic colour}

The role of emotional valence (positive vs. negative) on synaesthetic experience was examined both for the emotional words and for names of acquaintances. For the emotional words that elicited a colour, the stimuli were divided into those with positive and negative emotional connotations according to the ratings of Brown and Ure (1969) and the frequency of occurrence of colours was tabulated. Table 1 shows that words associated with positive emotions tend to elicit synaesthetic colours of pink, orange, yellow, and green, whereas words associated with negative emotions elicit synaesthetic colours of brown, grey, and black. Blue tended to be associated more with neutral words, and white tended not to cluster with any particular emotional valence. There were too few responses, divided over too many colour categories in order to analyse this statistically and so the data should only be interpreted as a trend.

For the people's names there is no a priori way of categorising them according to emotional valence because it depends on GW's own interpretation. For 29 names that had previously been shown to elicit consistent colours she was asked to classify each person according to whether she was, on balance, positively or negatively disposed to them, or neutral. This was done in a separate session from that in which the corresponding colours had been noted. The distribution of colours are displayed in Table 2. Although there are some similarities with

Table 1. Distribution of GW's synaesthetic colour responses to words as a function of emotional valence

\begin{tabular}{lccc}
\hline & Positive & Neutral & Negative \\
\hline Yellow & 5 & 1 & \\
Pink/purple & 4 & 1 & \\
Orange & 2 & & \\
Green & 4 & & 3 \\
Red & 4 & 3 & \\
Blue & & 2 & 2 \\
White & 1 & 1 & 2 \\
Brown & & 1 & 3 \\
Grey/silver & 1 & 1 & 7 \\
Black & & & \\
\hline
\end{tabular}


Table 2. Distribution of synaesthetic colours for people's names as a function of whether $G W$ is, on balance, positively or negatively disposed to that person or neutral towards them

\begin{tabular}{lccc}
\hline & Positive & Neutral & Negative \\
\hline Yellow & & 1 & \\
Pink/purple & 3 & 2 & \\
Orange & & 2 & \\
Green & 4 & & \\
Red & & 5 & \\
Blue & 2 & 2 & \\
White & 2 & 2 & \\
Brown & & & \\
Grey/silver & & & \\
Black & 1 & & \\
\hline
\end{tabular}

the emotional words (e.g., "blue" being the most common response for neutral affect, "green" more associated with positive affect), it is unwise to draw too many strong parallels given the low number of responses in some categories.

\section{GENERAL DISCUSSION}

This study documents a case of synaesthesia, GW, who reports synaesthetic photisms in response to people known to her and to other emotion-eliciting stimuli. There are a number of lines of evidence to suggest that GW is a genuine synaesthete. First of all, she does not seem to be reporting verbal colour associations based on general knowledge because many stimuli (e.g., colour names, food) elicit no synaesthesia in spite of having obvious colour associations. Second, she is more consistent over time than control subjects given memory instructions for those stimuli. Third, these colour responses appear to be automatic insofar as they are susceptible to Stroop-like interference.

Christian names are more likely to induce a report of a synaesthetic photism than other semantic categories, but this appears to depend almost entirely on whether GW is personally acquainted with someone of that name. The names that do not elicit synaesthetic photisms are still familiar names to her (e.g., Anne, Edward). She also reports the phenomenon when presented with people's faces, although this was not tested in this study, partly because we did not have access to photographs of her friends or family. We hope to explore this in future studies with GW and with other synaesthetes that report this phenomenon.

Ramachandran and Hubbard (2001a) briefly report a case of a synaesthete who experienced colours in response to faces. They interpreted this in terms of cross-activation between the righthemisphere face recognition area and the nearby right-hemisphere V4 colour region. There may well exist some cases of synaesthesia that can be accounted for in this way. In order to explain GW's pattern, however, one would need to assume that people's names automatically trigger their face representations. This may not be so implausible. Similar claims have indeed been made for another type of synaesthesia in which spoken words appear to activate colours via an intermediate specification of the word's orthographic or visual form (e.g., Paulesu et al., 1995). However, there are other aspects of GW's synaesthesia which suggest that the colours are indeed related to emotions rather than faces. Words that have an emotional connotation also elicit synaesthetic colours, and the valence of the emotion may have some influence over the colour. The latter may provide the mechanism by which new acquaintances can acquire synaesthetic colours.

This study resembles a number of others that were reported in the historical literature on synaesthesia. The most striking similarities between this study and the historical ones are the role that personal acquaintance can play, and also the effect of emotionality (e.g., Collins, 1929; Riggs \& Karwoski, 1934). However, the earlier reports were generated in a climate in which there was no emphasis placed on statistically quantifying these effects, or providing objective measures that could distinguish between synaesthetes and control subjects. In the present study, it has been demonstrated statistically that emotionality predicts the presence of a colour response more than other potentially relevant dimensions (e.g., how imageable the word is) and it has been shown that GW's colour associations differ from those generated by control subjects in terms of both consistency and automaticity. 
One other similarity between the present study and earlier ones is that there is some degree of correspondence between emotional valence and hue. Darker and less saturated colours (e.g., brown, black) tend to be associated with negative emotions and lighter and more saturated colours (e.g., yellow, green, red) tend to be associated with positive emotions (e.g., Collins, 1929; Cutsforth, 1925; Riggs \& Karwoski, 1934). Other forms of synaesthesia have also been described as having broadly consistent patterns across subjects. In pitch-colour synaesthesia, lower-pitched sounds tend to be darker and higher-pitched sounds tend to be brighter (Marks, 1975). In a series of experiments, Marks has shown that the same pitchbrightness trends are observed in matching tasks and metaphors produced by nonsynaesthetic individuals (Marks, 1982, 1984, 1987). This suggests that some forms of synaesthesia can be considered to be an exaggeration of normal, innate crossmodal mechanisms that are present in us all. The key difference is that the mechanism results in an automatically elicited conscious percept in the case of the synaesthete.

In everyday language, it is quite common to describe people in terms of colour. Asch (1955) noted that people are often described in terms of colours in languages as diverse as Chinese, Biblical Hebrew, Hansa (spoken in Sudan), and English. Moreover, cross-cultural studies of emotion-colour correspondences add some weight to the claims that there could be innate cross-modal associations. Pecjak (1970) found significant cross-cultural similarities between colour and emotions in countries such as USA, Japan, Turkey, and the former Yugoslavia. The cross-cultural associations were stronger for emotions than other classes of stimuli (e.g., days of the week). D'Andrade and Egan (1974) were able to produce comparable findings in a culture with minimal Western contact (the Tzeltal tribe of highland Central America). They used coloured chips rather than colour names and were keen to stress that the correspondences were due to dimensions within the colour space (e.g., brightness, saturation) rather than hue per se. These dimensions could provide the basic mechanism by which emotional concepts and familiar people could acquire synaesthetic colour in some individuals.

Although little is known about the neural basis of synaesthesia in general, and this type of synaesthesia in particular, it is possible to make some speculations. A number of researchers have suggested that synaesthesia may reflect a crosswiring or cross-activation of areas in the brain that would not normally, or only weakly, be connected (Baron-Cohen, 1996; Ramachandran \& Hubbard, 2001b). This could reflect a failure to remove certain connections early in life (Baron-Cohen, 1996). Although these innate predispositions may well be important, acquired knowledge (e.g., of people) can clearly tap into these mechanisms. A candidate region that has been implicated in both emotion and memory is the retrosplenial cortex (for a review, see Maddock, 1999). This region is known to respond both to personally familiar people relative to unfamiliar people (Shah et al., 2001) and to emotional words relative to neutral words (Maddock \& Buonocore, 1997), and has previously been implicated in synaesthesia (Nunn et al., 2002; Weiss et al., 2001). Its location in the medialposterior region of the brain also makes it an attractive candidate to interface with visual regions.

Finally, the special ability of certain individuals to perceive the coloured auras of other people has held an important place in folk psychology and mysticism throughout the ages. In some instances, there are clear parallels with what has been published in the scientific literature on synaesthesia over the last century. For instance, consider the following quote from $A$ Witches' Bible: “The sensitive is psychically aware of character qualities, or emotional or spiritual states, in the subject, and this awareness presents itself to him or her as visual phenomena" (p. 271; Farrar \& Farrar, 1981). Although many people claiming to have such powers could be charlatans, it is also conceivable that others are born with a "gift" of synaesthesia. GW does not believe that she has mystical powers and has no interest in the occult. However it is not hard to imagine how, in a different cultural and social environment or a different age, such an interpretation could arise. Rather than assuming that people give off auras or energy fields that can only 
be detected by rigged cameras or trained seers (e.g., Bagnall, 1937; Kilner, 1911), we need only assume two things to have a "scientific" account of the phenomenon in terms of synaesthesia. First, we need to assume that people with whom we are well acquainted and certain other stimuli (e.g., emotionally loaded words) can trigger an emotional response in the perceiver (e.g., Shah et al., 2001). Second, we need to assume that certain synaesthetic individuals have an exaggerated cross-wiring (or some other neural mechanism) between centres involved in emotional processing and colour perception, which enables the emotion-inducing stimulus to explicitly acquire this novel dimension. The former is taken for granted by most cognitive scientists. The latter is a conjecture on the basis of the findings from this case study.

Manuscript received 27 January 2003 Revised manuscript received 23 June 2003 Revised manuscript accepted 15 July 2003

\section{REFERENCES}

Asch, S. E. (1955). On the use of metaphor in the description of persons. In $\mathrm{H}$. Werner (Ed.), On expressive language. Worcester, MA: Clark University Press.

Bagnall, O. (1937). Origin and properties of the human aura. New York: E.P. Dutton.

Baron-Cohen, S. (1996). Is there a normal phase of synaesthesia in development? Psyche, 2, 27.

Baron-Cohen, S., Harrison, J., Goldstein, L. H., \& Wyke, M. (1993). Coloured speech perception: Is synaesthesia what happens when modularity breaks down? Perception, 22, 419-426.

Baron-Cohen, S., Wyke, M. A., \& Binnie, C. (1987). Hearing words and seeing colours: An experimental investigation of a case of synaesthesia. Perception, 16, 761-767.

Brown, W. P., \&Ure, D. M. J. (1969). Five rated characteristics of 650 word association stimuli. British Journal of Psychology, 60, 233-249.

Carroll, J. B., Davies, P., \& Richman, B. (1971). Word frequency book. New York: American Heritage Publishing.
Collier, G. L. (1996). Affective synaesthesia: Extracting emotion space from simple perceptual stimuli. Motivation and Emotion, 20, 1-32.

Collins, M. (1929). A case of synaesthesia. Journal of General Psychology, 2, 12-27.

Cutsforth, T. D. (1925). The role of emotion in a synaesthetic subject. American Journal of Psychology, 36, 527-543.

Cytowic, R. E. (1989). Synaesthesia: A union of the senses. New York: Springer.

D'Andrade, R., \& Egan, M. (1974). The colors of emotions. American Ethnologist, 1, 49-63.

Farrar, J., \& Farrar, S. (1981). A witches' bible: The complete handbook. Blasne, WA: Phoenix Publishing.

Grossenbacher, P. G., \& Lovelace, C. T. (2001). Mechanisms of synaesthesia: Cognitive and physiological constraints. Trends in Cognitive Sciences, 5, 36-41.

Harrison, J. (2001). Synaesthesia: The strangest thing. Oxford: Oxford University Press.

Kilner, W. J. (1911). The human atmosphere [later reprinted as The aura]. York Beach, MA: Samuel Weiser.

Maddock, R. J. (1999). The retrosplenial cortex and emotion: New insights from functional neuroimaging of the human brain. Trends in Neuroscience, 22, 310316.

Maddock, R. J., \& Buonocore, M. H. (1997). Activation of left posterior cingulate gyrus by the auditory presentation of threat related words: An fMRI study. Psychiatry Research, 75, 1-14.

Marks, L. E. (1975). On coloured-hearing synaesthesia: Cross-modal translations of sensory dimensions. Psychological Bulletin, 82, 303-331.

Marks, L. E. (1982). Bright sneezes and dark coughs, loud sunlight and soft moonlight. Journal of Experimental Psychology: Human Perception and Performance, 8, 177-193.

Marks, L. E. (1984). Synesthesia and the arts. In W. R. Crozier \& A. J. Chapman (Eds.), Cognitive processes in the perception of art. Amsterdam: North Holland/ Elsevier Science.

Marks, L. E. (1987). On cross-modal similarity: Auditory-visual interactions in speeded discrimination. Journal of Experimental Psychology: Human Perception and Performance, 13, 384-394.

Masson, D. I. (1952). Synesthesia and sound spectra. Word, 8, 39-41.

Mattingley, J. B., Rich, A. N., \& Bradshaw, J. L. (2001). Unconscious priming eliminates automatic binding of colour and alphanumeric form in synaesthesia. Nature, 410, 580-582. 
Mills, C. B., Boteler, E. H., \& Oliver, G. K. (1999). Digit synaesthesia: A case study using a Stroop-type test. Cognitive Neuropsychology, 16, 181-191.

Myers, C. S. (1911). A case of synaesthesia. British Journal of Psychology, 4, 228-238.

Nelson, H. E. (1985). National Adult Reading Test. London: NFER-Nelson.

Nunn, J. A., Gregory, L. J., Brammer, M., Williams, S. C. R., Parslow, D. M., Morgan, M. J., Morris, R. G., Bullmore, E. T., Baron-Cohen, S., \& Gray, J. A. (2002). Functional magnetic resonance imaging of synesthesia: Activation of V4/V8 by spoken words. Nature Neuroscience, 5, 371-375.

Odgaard, E. C., Flowers, J. H., \& Bradman, H. L. (1999). An investigation of the cognitive and perceptual dynamics of a colour-digit synaesthete. Perception, 28, 651-664.

Paulesu, E., Harrison, J., Baron-Cohen, S., Watson, J. D. G., Goldstein, L., Heather, J., Frackowiak, R. S. J., \& Frith, C. D. (1995). The physiology of coloured hearing: A PET activation study of colour-word synaesthesia. Brain, 118, 661-676.

Pecjak, V. (1970). Verbal synesthesiae of colors, emotions, and days of the week. Journal of Verbal Learning and Verbal Behavior, 9, 623-626.

Raines, T. H. (1909). Report of a case of psychochromesthesia. Journal of Abnormal Psychology, 4, 249-260.

Ramachandran, V. S., \& Hubbard, E. M. (2001a). Psychophysical investigations into the neural basis of synaesthesia. Proceedings of the Royal Society of London B, 268, 979-983.
Ramachandran, V. S., \& Hubbard, E. M. (2001b). Synaesthesia: A window into perception, thought and language. Journal of Consciousness Studies, 8, 3-34.

Riggs, L. A., \& Karwoski, T. (1934). Synaesthesia. British Journal of Psychology, 25, 29-41.

Shah, N. J., Marshall, J. C., Zafiris, O., Schwab, A., Zilles, K., Markowitsch, H. J., \& Fink, G. R. (2001). The neural correlates of person familiarity: A functional magnetic resonance imaging study with clinical applications. Brain, 124, 804-815.

Smilek, D., \&Dixon, M. J. (2002). Towards a synergistic understanding of synaesthesia: Combining current experimental findings with synaesthetes' subjective descriptions. Psyche, $8,01$.

Ward, J., \& Simner, J. (2003). Lexical-gustatory synaesthesia: Linguistic and conceptual factors. Cognition, 89, 237-261.

Ward, J., Simner, J., \& Auyeung, V. (in press). A comparison of lexical-gustatory and grapheme-colour synaesthesia. Cognitive Neuropsychology.

Warrington, E. K. (1996). The Camden Memory Tests. Hove, UK: Psychology Press.

Weiss, P. H., Shah, N. J., Toni, I., Zilles, K., \& Fink, G. R. (2001). Associating colours with people: A case of chromatic-lexical synaesthesia. Cortex, 37, 750-753.

Whipple, G. M. (1900). Two cases of synaesthesia. American Journal of Psychology, 11, 377-404. 